\title{
Prevalence of Asthma among Patients with Allergic Rhinitis - A Cross Sectional Study
}

\author{
Mohamed Izudheen Irshad K. ${ }^{1}$, Aji Mathew Joseph ${ }^{2}$ \\ ${ }^{1}$ Department of Pulmonology, KIMS Alshifa Hospital, Perinthalmanna, Kerala, India. \\ ${ }^{2}$ Department of Pulmonology, Believers Church Medical College Hospital, Thiruvalla, Kerala, India.
}

\section{ABSTRACT}

\section{BACKGROUND}

Approximately $10-30 \%$ of population suffers from allergic rhinitis during their lifetime. In India, more than $10 \%$ of the population is reported to have one or other type of allergic disorder. Nasal symptoms are often demeaned; however, their prevalence and effect on the quality of life justify an aggressive and rational approach. Rhinitis and asthma frequently co-exist [60-70\%] with rhinitis appearing first in $45 \%$ of patients. We wanted to study prevalence of bronchial asthma in patients of allergic rhinitis with or without chest symptoms and its correlates.

\section{METHODS}

This is a cross sectional study conducted among 100 cases of allergic rhinitis who presented to our hospital from December 2010 to August 2012. Data was analysed by using SPSS and results were expressed in percentages.

\section{RESULTS}

Maximum number of patients belonged to the age group between 21 - 25 yrs. (34 patients), where males were $38.18 \%$ and females were $28.89 \%$. Majority of the patients (74\%) had significantly reversible small airways obstruction. Among the patients with allergic rhinitis, males had predominantly chest symptoms (58.33\%) compared to females $(41.67 \%)$. Spirometry revealed $63(80.77 \%)$ patients had mild obstruction, 12 (15.38\%) had moderate obstruction and $3(3.85 \%)$ had severe obstruction. The prevalence of asthma among allergic rhinitis was found to be $78 \%$ in our study.

\section{CONCLUSIONS}

$78 \%$ of patients with allergic rhinitis were found to have underlying asthma. Prevalence of severe, moderate, and mild asthma amongst patients of allergic rhinitis was found to be $3 \%, 12 \%$ and $63 \%$ respectively. Severe obstruction was observed in $3.85 \%$ of subjects.

\section{KEY WORDS}

Asthma, Allergic Rhinitis, Spirometry, Chest Symptoms, Obstruction
Corresponding Author:

Aji Mathew Joseph,

Assistant Professor,

Department of Pulmonology,

Believers Church Medical College Hospital,

Thiruvalla-689103, Kerala, India.

E-mail:ajizzz9@gmail.com

DOI: $10.14260 / \mathrm{jemds} / 2020 / 434$

How to Cite This Article:

Irshad MIK, Joseph AM. Prevalence of asthma among patients with allergic rhinitis- a cross sectional study. J. Evolution Med. Dent. Sci. 2020;9(28):1992-1996, DOI: 10.14260/jemds/2020/434

Submission 28-02-2020,

Peer Review 05-06-2020,

Acceptance 11-06-2020,

Published 13-07-2020.

Copyright (C) 2020 JEMDS. This is an open access article distributed under Creative Commons Attribution License [Attribution 4.0 International (CC BY 4.0)] 


\section{BACKGROUND}

The prevalence of allergic disorders is increasing worldwide. While genetic factors have probably not changed, environmental factors have altered markedly. On one hand, environmental pollution has increased with potentially adverse effects on the impact of environmental allergens. On the other hand, excess hygiene and limited exposure to microbial antigens may also be responsible for the higher rate of development of allergic disorders. Every day, millions of children wake up suffering from the symptoms of nasal/respiratory allergies. Likewise, many experiences the suffering of the vicious cycle of "scratch-itch scratch" due to allergic skin conditions. Now it is widely recognized that disease means more than just symptoms. The global impact on an individual's daily function and ability to enjoy life is also very important, sometimes more critical than the symptoms themselves.

Allergic disorders are associated with learning disabilities, fatigue, and lack of concentration, sleep disturbances and loss days from school. In utero, $\mathrm{T}$ cells of foetus are primed by common environmental allergens that cross placenta. Type 2 helper $\mathrm{T}$ cells dominate immune response of virtually all newborn infants. The normal non-atopic infant's immune system, during subsequent development shifts in favour of Type 1 helper $\mathrm{T}$ cell mediated responses to inhaled allergens (process termed "immune deviation"), whereas in the potentially atopic infant there is a further increase in Type 2 helper $\mathrm{T}$ cells that were primed in utero. The progressive development of allergy seen through childhood in the form of atopic dermatitis, food allergy, allergic rhinitis, childhood asthma, adult asthma is referred to as "The Allergy March". Total IgE, a marker of allergic diseases peaks in 2nd decade, after that it begins to decrease. ${ }^{1,2}$

Atopy is the inherited tendency to develop IgE mediated immune responses, which places a person at greater risk for developing certain allergic diseases such as allergic rhinitis, asthma, atopic dermatitis. ${ }^{1,3}$ Histamine is a crucial mediator in the pathophysiology of early and late phase reactions of an allergic response, playing important roles in cytokine release and in the adhesion process. ${ }^{4}$ In India, more than $10 \%$ of the population is reported to have one or other type of allergic disorder.

Two studies conducted in Bombay, concluded that incidence of atopy in the Indian population is as high as $25.3 \% .5,6$ The prevalence of allergic rhinitis is estimated to range from $10 \%$ to $20 \%$ in the USA and Europe. ${ }^{7}$ Allergic rhinitis [called Asatmyaja Pratisyaya in Indian medicine] with its attendant complications is a common condition today as the nasal passages are among the chief source of contact of man with allergens. Allergic rhinitis is defined as an allergen induced inflammation of the membranes lining the nose. It is characterized by nasal congestion, rhinorrhoea, sneezing, itching of nose and/or postnasal drainage. ${ }^{8}$

Based on the nature of symptoms ARIA (Allergic Rhinitis and its Impact on Asthma) working group has classified allergic rhinitis into intermittent, persistent, mild and moderate-severe types and recommended for assessment of asthma in patients with persistent rhinitis, assessment of rhinitis in patients with persistent asthma and appropriate therapeutic strategy to combine safe and effective management of the upper and lower airway. ${ }^{9}$

Multiple factors contribute to the wide range of reported prevalence rates. These include type of prevalence rate reported, study selection criteria, age of participants, differences in survey methods, varied geographic locations and socioeconomic status, any of which are significant enough to confound direct comparison between studies. There are no standard set of diagnostic criteria for allergic rhinitis. It constitutes approximately 55\% of all allergies seen in India. ${ }^{10}$

A recent survey carried out in India shows that $20-30 \%$ of the population suffer from allergic rhinitis and that $15 \%$ develop asthma.11,12 Approximately $10-30 \%$ of population suffers from allergic rhinitis during their life time.13,14 Nasal symptoms are often demeaned; however, their prevalence and effect on the quality of life justify an aggressive and rational approach. Rhinitis and asthma frequently co-exist [60-70\%] with rhinitis appearing first in $45 \%$ of patients. ${ }^{10}$ Although a cause of significant widespread morbidity, allergic rhinitis is often viewed rather erroneously as trivial disease.

In India, it is often treated as an 'orphan' disease as AR falls in the grey area between the otorhinolaryngologist and the pulmonologist resulting in lack of focus on research in allergic rhinitis by both the specialties. The prevalence of asthma in patients with rhinitis ranges from $15 \%-40 \%$ and is present in $10 \%-15 \%$ of the patients with seasonal rhinitis and in $25 \%$ $40 \%$ of those with persistent rhinitis. The severity of rhinitis is directly related to asthma severity and develops before age of 20 years in $80 \%$ of cases with mean age of onset of 10 years and peak incidence of 13-19 years. ${ }^{15}$

The Control of Allergic Rhinitis and Asthma Test has been proposed as the first tool to implement the Allergic Rhinitis and its Impact on Asthma initiative guidelines in clinical practice. The "Control of Allergic Rhinitis and Asthma Test" (CARAT) is a brief self-administered questionnaire to quantify the degree of control of Allergic Rhinitis and Asthma. CARAT can be used both in clinical studies and in clinical practice, to compare groups and to evaluate individual patients over time. ${ }^{16}$ Reports from India shows that 1 out of every 6 person has allergic rhinitis. ${ }^{17}$ Raichur is one of the backward districts of Karnataka and highly polluted. So, the current study intended to determine the prevalence of bronchial asthma in patients with allergic rhinitis with or without chest symptoms.

In our study we intent to determine the prevalence of bronchial asthma in patients with allergic rhinitis with or without chest symptoms by degree of bronchodilator response and to correlate clinical and spirometric parameters of these patients in our clinical setting under Indian scenario.

\section{METHODS}

It was a cross sectional study conducted in our department from December 2010 to August 2012. Only those patients with history suggestive of allergic rhinitis and who were able to successfully complete spirometry along with other inclusion criteria were enrolled in our study. Those who did not meet inclusion criteria and patients who did not give consent were not included in the study. A total of hundred allergic rhinitis 
patients fitted into our inclusion criteria. Clinical diagnosis of allergic rhinitis was made after a detailed clinical history and physical examination. Symptoms of paroxysms of sneezing, nasal pruritus, rhinorrhoea and nasal blockage daily for the last two weeks were considered to have allergic rhinitis. Patients with history of fever, purulent nasal discharge or sputum, respiratory infection in the month prior to study, Patients with other ENT problems like DNS, polyps, smokers, patients with known heart disease, patients on treatment with steroids (intranasal/oral), patients on leukotriene modifiers were excluded from the study.

All the patients included in the study underwent the following Investigations

a. Complete haemogram.

b. Absolute Eosinophil Count.

c. X ray - Chest.

d. X ray - PNS.

e. Serum total IgE level.

f. Spirometry.

\section{Ethics}

Permission was obtained from the institutional ethical committee regarding conducting this study. Informed written consent was taken from patients fulfilling the eligibility criteria and been informed about type of study and assurance was given for maintenance of confidentiality of the patient.

\section{Statistical Analysis}

It was a cross sectional study. Chi square test was used to find the association. A p value $<0.05$ was taken as significant. Data analysis was done using software SPSS v16.0 and results were expressed in percentages.

\section{RESULTS}

\begin{tabular}{|c|c|c|c|}
\hline \multirow[b]{2}{*}{ Age (Yrs.) } & \multicolumn{2}{|c|}{ Sex } & \multirow{2}{*}{ Total } \\
\hline & Female & Male & \\
\hline $16-20$ & 7 (15.5\%) & $5(9 \%)$ & $12(12 \%)$ \\
\hline $21-25$ & $13(28.8 \%)$ & $21(38.1 \%)$ & $34(34 \%)$ \\
\hline $26-30$ & $11(24.4 \%)$ & $15(27.2 \%)$ & $26(26 \%)$ \\
\hline $31-35$ & $7(15.5 \%)$ & $11(20 \%)$ & $18(18 \%)$ \\
\hline $36-40$ & 7 (15.5\%) & $3(5.4 \%)$ & 10 \\
\hline Total & 45 & 55 & 100 \\
\hline \multicolumn{4}{|c|}{ Table 1. Distribution of Subjects According to Age and Sex } \\
\hline
\end{tabular}

Among the total 100 Allergic rhinitis patients studied, the age group varied from 16 to 40 years. The maximum number of patients belonged to the age group between 21-25 yrs. (34) where males were $38.18 \%$ and females were $28.89 \%$. Minimum number of patients belonged to the age group between $36-40$ yrs., (10) where males were $15.56 \%$ and females were $5.45 \%$. Males were predominant than females in all the age groups. Mean age of study subjects was $27.78 \pm 6.01$ years.

\begin{tabular}{|ccc|}
\hline Spirometry Pattern & Number & Percent (\%) \\
Normal & 22 & $22 \%$ \\
Restriction & 24 & $24 \%$ \\
Obstruction & 54 & $54 \%$ \\
Small airways obstruction & 74 & $74 \%$ \\
\hline Table 2. Distribution of Subjects According to Spirometry Pattern \\
\hline
\end{tabular}

Among the 78 (78\%) patients who had asthma, the majority of the patients (74\%) had significantly reversible small airways obstruction. 54 patients (54\%) had obstructive flow pattern on spirometry whereas $24(24 \%)$ had restrictive flow pattern in combination with obstruction on spirometry. Of the 100 patients who underwent spirometric assessment of the pulmonary function, $22 \%(\mathrm{n}=22)$ had normal baseline study, $24 \%(n=24)$ had restrictive pattern and $54 \%(n=54)$ had obstructive pattern. Among the patients with obstructive pattern, small airway obstruction was seen in majority (74\%, $\mathrm{n}=74$ ).

\begin{tabular}{|c|c|c|c|}
\hline Sex & $\begin{array}{r}\text { Allergic Rhin } \\
\text { Without }\end{array}$ & $\begin{array}{l}\text { est Symptoms } \\
\text { With }\end{array}$ & Total \\
\hline Female & 20 & 25 & 45 \\
\hline Male & 20 & 35 & 55 \\
\hline Total & $40(40 \%)$ & $60(60 \%)$ & 100 \\
\hline \multicolumn{4}{|c|}{ Table 3. Association of Study Group Based on Chest Symptoms } \\
\hline
\end{tabular}

Among the study group, 60 patients with allergic rhinitis had chest symptoms in the form of cough, chest tightness and wheeze whereas 40 patients did not give history of chest symptoms. Among the patients with allergic rhinitis males had predominant chest symptoms (58.33\%) compared to females (41.67\%).

\begin{tabular}{|c|c|c|c|}
\hline \multirow[b]{2}{*}{ Severity of Asthma } & \multicolumn{2}{|c|}{ Sex } & \multirow{2}{*}{ Tota } \\
\hline & Female & Male & \\
\hline Mild & 26 & 37 & 63 \\
\hline Moderate & 4 & 8 & 12 \\
\hline Severe & 2 & 1 & 3 \\
\hline Total & $32(41.02 \%)$ & 46 (58.97\%) & 78 \\
\hline
\end{tabular}

Among the 78 patients who were diagnosed as asthmatics on the basis of spirometry, $63(80.77 \%)$ patients had mild obstruction, 12 , (15.38\%) had moderate obstruction and 3 (3.85\%) had severe obstruction. Of the total 78 patients diagnosed of asthma, males accounted for 46 (58.97\%) whereas females were 32 (41.02).

\begin{tabular}{|ccccc|}
\hline Severity & AR & Mild (\%) & $\begin{array}{c}\text { Asthma severity } \\
\text { Moderate (\%) }\end{array}$ & Severe (\%) \\
Mild & 31 & $19(61.3)$ & - & - \\
Moderate & 35 & $23(65.7)$ & $4(11.4)$ & - \\
Severe & 34 & $21(61.7)$ & $8(23.5)$ & $3(8.8)$ \\
Total & $\mathbf{1 0 0}$ & $\mathbf{6 3}$ & $\mathbf{1 2}$ & $\mathbf{3}$ \\
\hline Table 5. Relationship between Severity of Allergic Rhinitis (AR) \\
and Severity of Bronchial Asthma \\
\hline \multicolumn{5}{r}{}
\end{tabular}

In 31\% ( $\mathrm{n}=31$ ) of mild allergic rhinitis patients 19 patients $(61.3 \%)$ had mild asthma whereas, $35 \%$ cases $(n=35)$ of moderate allergic rhinitis patients 23 patients (65.7\%) had mild asthma and 4 patients (11.4\%) had moderate asthma. In $34 \%(n=34)$ cases of severe allergic rhinitis patients, 21 patients $(61.7 \%)$ had mild asthma, 8 patients (23.5\%) patients had moderate asthma and 3 patients $(8.8 \%)$ had severe asthma.

\begin{tabular}{|cccc|}
\hline $\begin{array}{c}\text { Allergic Rhinitis and } \\
\text { Chest Symptoms }\end{array}$ & Yes & Asthma & Total \\
With & 51 & No & 60 \\
Without & 27 & 13 & 40 \\
Total & $\mathbf{7 8}(\mathbf{7 8 \% )}$ & $\mathbf{2 2}(22 \%)$ & 100 \\
\hline \multicolumn{3}{r|}{ Table 6. Prevalence of Bronchial Asthma } \\
\\
in Relation to Chest Symptoms \\
\hline
\end{tabular}

In our study, $78 \%(\mathrm{n}=78)$ had bronchial asthma where as $22 \%(n=22)$ did not have asthma, according to the methods 
adopted. The prevalence of asthma in AR patients with chest symptoms were found to be $65.4 \%(n=51)$ and without chest symptoms is $34.6 \%(\mathrm{n}=27)$. There was a Relative risk of 1.26 (95\% CI $=0.99-1.60)$ among the AR patients to develop asthma calculated with a chi square test showing a significant association of 3.33 with $\mathrm{df}=1(\mathrm{p}<0.05)$.

\section{DISCUSSION}

In the present study, Allergic rhinitis was more common in the younger age group. This is in accordance with the published literature that allergic disorders predominate in the younger people with 0-40 year group and particularly the most productive years of life, constituting $80 \%$ of patients, resulting in a huge loss to the society. ${ }^{10,18,19}$ Among AR patients, studies show that there is an equal sex distribution or male predominance among children and equal sex distribution or slight female predominance among adults. The male predominance in our study is probably due to sampling induced by the social status of women in our society. Females tend to endure their suffering while males may seek medical attention.

Most of our patients presented with classical symptoms of allergic rhinitis like paroxysms of sneezing, nasal discharge, nasal block, itching and eye symptoms. Similarly Yadav SPS et al. in their study among 1075 patients of AR reported sneezing, nasal discharge and nasal block as the commonest symptoms followed by itching and eye symptoms. ${ }^{20}$ In a study done by Seedat RY et al. among 100 patients of AR, nasal block was the commonest symptom (80\%) followed by nasal discharge, sneezing, pruritus and postnasal drip. ${ }^{21}$ Cough was also common symptom among our patients. Cough in allergic rhinitis patients could be due to postnasal drip, pharyngitis or lower airway obstruction. Postnasal drip is the commonest cause of cough in allergic rhinitis. Since it is difficult to ascertain that cough was due to upper or lower airway involvement, we considered only chest tightness and wheeze to evaluate chest symptoms in our study. $41 \%$ of our patients gave history of chest tightness and/or wheeze sometime during the illness though it may not be their presenting complaints. These patients had more severe rhinitis and airway obstruction than those who did not complain, and it can be considered as a risk factor for development of asthma. There are more patients who rated their symptoms as moderate to severe. This is probably due to the patients with milder symptoms may not be seeking medical help or are not being recognized or are being treated by general practitioners.

Allergic rhinitis patients are more likely to have abnormal spirometry than normal subjects. Small airway dysfunction is the most common abnormality. FEF-25-75, FEF 25 and FEF-50 are sensitive indicators. Patients with more severe AR have more severe airway dysfunction. Spirometric abnormalities were highest in the third decade when rhinitis symptoms were also peaking. Therefore, it is important to perform the test when the patient is having rhinitis symptoms. The bronchoconstriction may be mediated by neuro-humoral mechanisms (nasobronchial reflex through vagus), postnasal drainage of inflammatory material into lower airways, loss of air conditioning and aeroallergen trapping due to mouth breathing as result of nasal obstruction. Grossman and Putnam performed pulmonary function tests on 32 patients with allergic rhinitis and found that, at baseline $13 \%$ of patients had obstruction at low lung volumes (maximum mid expiratory flow and maximum terminal flow). This was lower than that in our study, however their sample size was smaller and they have not specified the severity of allergic rhinitis. ${ }^{22}$ Morgan and Hall studied Dynamic compliance at varying respiratory frequencies, closing capacity, residual volume and maximum expiratory flow volume curves in subjects with symptoms of hay fever. Frequency dependence of compliance was found in $40 \%$ of patients even when expiratory flow rates at mid vital capacity were within the predicted range of all subjects. Subclinical airway obstruction is present even when spirometric tests are in normal limits. ${ }^{23}$

The prevalence of asthma in AR patients with chest symptoms were found to be $65.4 \%(n=51)$ and without chest symptoms is $34.6 \%(\mathrm{n}=27)$. From literature, the prevalence of asthma in patients with rhinitis ranges from $15 \%$ to $40 \% .15$ Our study had a higher prevalence (78\%) of asthma (reversible airway disease) among the patients with allergic rhinitis. This could be due to the fact that small airways reversibility was considered as a parameter to diagnose asthma in the present study and the majority of our patients had small airways obstruction. Recent research suggests that FEF $25-75 \%$ or FEF $25-50 \%$ may be a more sensitive parameter than FEV1 in the detection of obstructive small airway disease. ${ }^{24,25}$ Present being a prevalence study, the patients who initially present with chest symptoms with history of allergic rhinitis were taken into the study could be another possible explanation. Previous studies tell us that the severity of rhinitis is directly related to severity of asthma ${ }^{15}$ which was also observed in our study. $24 \%$ of our patients had restrictive abnormality at baseline, though $74 \%$ of them also had concomitant small airway involvement. There were no studies regarding restrictive abnormality among AR patients. We hypothesized this restriction could be due to FVC limitation either secondary to poor effort due to severity of nasal symptoms or secondary to underlying small airway dysfunction present in these patients. However, these patients need further evaluation with appropriate investigations to know the cause of restriction. Irrespective of pre bronchodilator spirometry results, degree of bronchodilator response was higher in allergic rhinitis. The response was intermediate to that of normal and asthmatic patients. Thus, the airway obstruction in allergic rhinitis is largely reversible and patients will benefit with,

a. Optimal control of allergic rhinitis.

b. Additional use of bronchodilator and inhaled corticosteroids in those with severe allergic rhinitis with chest symptoms.

\section{CONCLUSIONS}

Patients with allergic rhinitis are at risk of developing asthma. Both allergic rhinitis, and asthma cause significant morbidity and loss of quality of life. It is therefore essential to diagnose early because it is possible to modify the course of the disease with adequate therapy. $78 \%$ of patients with allergic rhinitis were found to have underlying asthma. Prevalence of severe, moderate, and mild asthma amongst patients of allergic rhinitis was found to be $3 \%, 12 \%$ and $63 \%$ respectively. 
Severe obstruction was observed in $3.85 \%$ of subjects. Among the patients with allergic rhinitis, males had predominantly chest symptoms compared to females.

Pulmonary function test abnormalities are present even when patients do not complain of chest symptoms. Therefore, in allergic rhinitis patients, asthma should be carefully investigated, and they should undergo pulmonary function tests as a baseline investigation to detect occult asthma, more so in allergic rhinitis patients who have chest symptomatology.

\section{REFERENCES}

[1] Kay AB. Allergy and allergic diseases. First of two parts. N Engl J Med 2001;344 (1):30-7.

[2] Weinberg EG. The atopic march. Curr Allergy Clin Immunol 2005;18 (1):4-5.

[3] Stanaland BE. Treatment of allergic rhinitis and its comorbidities. Medscape CME 2003.

[4] Jutel M, Blaser K, Akdis CA. The role of histamine in regulation of immune responses. Chem Immunol Allergy 2006;91:174-87.

[5] Shaik WA. Allergies and asthma in India: an analysis of 2467 patients seen over a six-year period. Indian J Clin Pract 1998;8 (12):23-6.

[6] Shaik WA. Allergies in India: an analysis of 1619 patients attending an allergy clinic in Bombay. Int Rev Allergol Clin Immunol 1997;3 (2):101-4.

[7] Ozdoganoglu T, Songu M. The burden of allergic rhinitis and asthma. Ther Adv Respir Dis 2012;6 (1):11-23.

[8] World Health Organisation - Fact Sheet. Indian J Chest Dis Allied Sci 2000;42:126-8.

[9] Bousquet J, Van Cauwenberge P, Khaltaev N, et al. Allergic rhinitis and its impact on Asthma. J Allergy Clin Immunol 2001;108 (5 Suppl):S147-334.

[10] Shaik WA. Allergic rhinitis in allergy and asthma - a clinical primer. New Delhi: IJCP 1999: p. 65.

[11] Anonymous: All India coordinated project on aeroallergens and human health. Report New Delhi: Ministry of Environment and Forests 2000.

[12] Chhabra SK, Gupta CK, Chhabra P, et al. Prevalence of bronchial asthma in schoolchildren in Delhi. J Asthma 1998;35 (3):291-6.
[13] Corren J. Allergic rhinitis and asthma: how important is the link? J Allergy Clin Immunol 1997;99 (2):S781-6.

[14] Chanez P, Vignola AM, Vic P, et al. Comparison between nasal and bronchial inflammation in asthmatic and control subjects. Am J Respir Crit Care Med 1999;159 (2):588-95.

[15] Serrano C, Valero A, Picado C. Rhinitis and asthma: one airway, one disease. Arch Bronconeumol 2005;41 (10):569-78.

[16] Fonseca JA, Nogueira-Silva L, Morais-Almeida M, et al. Control of allergic rhinitis and asthma test (CARAT) can be used to assess individual patients over time. Clin Transl Allergy 2012;2 (1):16.

[17] Shaikh WA. Allergic rhinitis; allergy and asthma: a tropical view. New Delhi: IJCP Publication 2001.

[18] Wittig HJ, Belloit J, De Fillippi I, et al. Age-related serum immunoglobulin E levels in healthy subjects and in patients with allergic disease. J Allergy Clin Immunol 1980;66 (4):305-13.

[19] Shaik WA, Shaik SW. Allergies in India: an analysis of 3389 patients attending an allergy clinic in Mumbai, India. J Indian Med Assoc 2008;106 (4):220.

[20] Yadav SPS, Goel HC, Chanda R, et al. A clinical profile of allergic rhinitis in Haryana. Indian J Allergy Asthma Immunol 2001;15 (1):13-5.

[21] Seedat R, Rautenbach J, Steenkamp G, et al. Allergen sensitivities of patients with allergic rhinitis presenting to the ENT clinic at Universitas Academic Hospital. Curr Allergy Clin Immunol 2006;19 (3):130-2.

[22] Putnam JS, Grossman J. Small airway obstruction in allergic rhinitis. J Allergy Clin Immunol 1975;55 (1):4955.

[23] Morgan EJ, Hall DR. Abnormalities of lung function in hay fever. Thorax 1976;31 (1):80-6.

[24] Simon MR, Chinchilli VM, Phillips BR, et al. Forced expiratory flow between $25 \%$ and $75 \%$ of vital capacity and FEV1/ forced vital capacity ratio in relation to clinical and physiological parameters in asthmatic children with normal FEV1 values. J Allergy Clin Immunol 2010;126 (3):527-34.

[25] Ciprandi G, Cirillo I. Forced expiratory flow between 25\% and $75 \%$ of vital capacity may be a marker of bronchial impairment in allergic rhinitis. J Allergy Clin Immunol 2011;127 (2):549. 